\title{
The Scholarship of Transformation: A Review of the Inaugural EuroSoTL Conference
}

\section{CORK, IRELAND, 7-9 JUNE 2015}

The Inaugural EuroSoTL conference, hosted by University College Cork (UCC), Ireland embraced the theme of bridging boundaries through the scholarship of teaching and learning. For three days, international scholars, academic developers, senior faculty, and students debated, interpreted, deciphered, and learned to challenge the tenets and principles of SoTL.

In his welcome address, the UCC Vice-President for Teaching and Learning, Professor John O'Halloran, elucidated the University philosophy by claiming that UCC is student focused, staff supported, and globally informed. This resonated with the vision for SoTL in which we, as a community of practice, work to research the dynamics of studentstaff relationships through multinational collaboration and scholarly activities. The conference coincided with the 200 year campus celebration of George Boole's birth, a distinguished mathematician, philosopher, logician, and first UCC mathematics professor, who left the world with the equations necessary for the technology it needs to progress.

The pre-conference workshops were well received, covering definitional and practice issues for SoTL as well as carefully dissecting and decoding disciplines by analysing bottlenecks and troublesome learning. These workshops inspired delegates to rethink teaching and learning practices by better positioning learning within a learner context. Delegates were able to continue debates and discussions at the welcome reception hosted in the historical setting of the staff common room.

The conference sessions provided a rich tapestry for unlocking the practices of SoTL by moving subtly through and within SoTL. Boyer's (1990) research on different scholarships provided an interesting backdrop to many of the debates within the conference. The conference further considered a tiered approach to scholarship emphasised within the keynote addresses, creatively delivered by leading scholars and practitioners such as Veronica Bamber, Kathy Takayama, Joelle Fanghanel, Pat Hutchings and Mick Healey. These addresses provided an adjunct to Boyer's conceptualisation of scholarship by considering the scholarship of uncertainty, challenge, fellowship, transition, transformation, studentship, and community engagement. These scholarship themes enabled delegates to disseminate their research in a dynamic and collegial way.

The learning from the conference was further emphasised in the poster presentations which illustrated the theme of unity through division, where SoTL scholars need to learn how best to manage the challenge of SoTL as we move forward in a quest to engage and disseminate more. 
The conference was a powerful meeting place for understanding and learning with and from the disciplines. SoTL is, and remains, an elusive concept, alien to most but dear to many. The importance of being part of a community that shares ideas, encourages development, influences change and researches impact on student engagement, exemplifies the vision of SoTL by living the philosophy of exclusive inclusivity.

What is the value of a conference? The inaugural EuroSoTL conference reminded us that it is not solely about the depth and detail of presentation that is important, but how we learn to work together to share ideas, consider collaboration, and make public the work we do within, and beyond, the disciplines. Through SoTL, we not only learn to bridge boundaries, but celebrate the bridges we build and the impact we make on student learning. This inaugural conference was a unique place where we came together, learned together, stayed together, ate together, and left together feeling energised, grounded and ready to consider, reflect, and realise the challenges ahead.

The conference was a huge success - well organised, carefully planned. It provided a platform for international scholars to continue their journey in Europe. The seed of EuroSoTL has been planted-we wait for Europe to cultivate the learning from the conference and continue to plant new seeds at future events. The International Society for the Scholarship of Teaching and Learning enables regions to develop common spaces to communicate and celebrate the work they do. The more spaces we have to share thoughts and research, the stronger the organisation will become. It is through doing that we learn to appreciate what doing does.

Earle Abrahamson is senior lecturer and teaching fellow at the University of East London and CoChair of ISSOTL Multinational Teaching Fellowship Special Interest Group.

\section{REFERENCES}

Boyer, E.L. (1990). Scholarship reconsidered: Priorities of the professoriate. Princeton, NJ: Carnegie Foundation for the Advancement of Teaching. 